\title{
Dialogía intergeneracional en la construcción de memorias acerca de la dictadura militar chilena*
}

\author{
Intergenerational Dialogism in the Construction of \\ Memories about the Chilean Military Dictatorship
}

Recibido: abril 8 de 2014 | Revisado: agosto 25 de 2014 | Aceptado: agosto 25 de 2014

\author{
María José Reyes ANDREANI ** \\ Universidad de Chile, Chile \\ Marcela Cornejo CANCINO *** \\ Pontificia Universidad Católica de Chile, Chile \\ María Angélica Cruz Contreras **** \\ Universidad de Valparaíso, Chile \\ Constanza CARRILlO $* * * * * *$ \\ PATRICIO CAVIEDES ******* \\ Universidad de Chile, Chile
}

doi:10.11144/Javeriana.upsy13-5.dicm

Para citar este artículo: Reyes, M. J., Cornejo, M., Cruz, M. A., Carrillo, C., \& Caviedes, P. Dialogía intergeneracional en la construcción de memorias acerca de la dictadura militar chilena. Universitas Psychologica, 14(1), 255-270. http://dx.doi. org/10.11144/Javeriana.upsy13-5.dicm

* Agradecemos a quienes generosamente participaron de los grupos de discusión. Este trabajo fue financiado por el Proyecto FONDECYT N ${ }^{\circ}$ 1110411 "Memorias de la dictadura militar: voces e imágenes en la dialogía intergeneracional

** Correo electrónico: mjrandreani@u.uchile.cl

**** Correo electrónico: marcela@uc.cl

*****Correo electrónico: mariaangelica.cruz@uv.cl

****** Correo electrónico: c.carr.magna@gmail.com

******** Correo electrónico: pat.caviedes@gmail.com

\section{RES UMEN}

La transmisión de memorias acerca de la violencia política es apremiante en sociedades que han vivido autoritarismos. Este artículo se focaliza en dicho problema, en el contexto de la dictadura militar chilena (1973-1990) y la memoria que actualmente se construye acerca de ella, a cuarenta años del golpe de Estado. Desde una perspectiva dialógica, se analiza el tipo de relación que se produce entre generaciones cuando hacen memoria de la dictadura militar. Se realizaron seis grupos de discusión, participando un total de 48 personas convocadas según: a) grupo etario, b) posición ideológica, c) nivel socioeconómico y d) territorio. El análisis discursivo releva la constitución de tres generaciones - protagonista del pasado, protagonista del presente y zona gris- que al hacer memoria de la dictadura adoptan como forma dialógica el debate, no realizando mayores cuestionamientos respecto de los contenidos considerados al momento de construir versiones de dicho pasado en la conversación.

Palabras clave

memorias sociales; transmisión; dialogía intergeneracional; dictadura militar chilena

\section{A B S T R A C T}

The transmission of memories about political violence is a pressing need in societies which have experienced authoritarian rule. The article focuses on this issue in the context of the Chilean military dictatorship (1973-1990) and the memory currently being constructed about it, forty years after the coup. From a dialogic perspective, the text analyzes the type of relationship established between generations when they think back about the military dictatorship. Six discussion groups were set up, with a total of 48 participants selected according to their a) age group, b) political stance, c) socioeconomic level, and d) territory. The discursive analysis reveals the establishment of three generations -protagonist of the past, protagonist of the present, and a gray area- whose members, when recalling the dictatorship, use debate as their dialogic form without truly questioning the contents employed to construct versions of this past in their conversations.

Keywords

social memories; transmission; intergenerational dialogism; Chilean military dictatorship 
Desde el ámbito de las ciencias sociales la preocupación hacia la memoria colectiva ha sido reciente, como señalase Traverso (2007) "en el transcurso de los años sesenta a setenta estaba prácticamente ausente del debate intelectual" (p. 13). Sin embargo, ello no ha sido razón para que la investigación en este ámbito no sea abundante.

En el caso del Cono Sur, los estudios se han enfocado a períodos caracterizados por gobiernos autoritarios donde la violación a los derechos humanos fue parte de la vida cotidiana. Y Chile no ha sido la excepción, más aún cuando el pasado reciente signado por la violencia y represión política instalada por la dictadura militar (1973-1990) sigue estando presente, condicionando las acciones y las proyecciones futuras.

Transcurridos más de veinte años de gobiernos post dictatoriales, y en el contexto de la conmemoración de los cuarenta años del golpe de Estado en Chile, una de las preocupaciones más apremiantes que se ha perfilado en el ámbito social y político es respecto a los 'legados del pasado' hacia las nuevas generaciones. ¿Qué olvidar?, ¿qué recordar?, serán preguntas centrales, más cuando se prevé un 'relevo generacional' (Aguilar, 2008), es decir, un recambio entre quienes vivieron los sucesos en primera persona y las nuevas generaciones.

Si se asume la memoria como una práctica social en tanto proceso intersubjetivo, contingente y contextual (Halbwachs 1968; 1925; Middleton \& Edwards, 1992; Vázquez 2001), cobra sentido abordar el problema de su transmisión desde una perspectiva dialógica, es decir, considerando que aquello que se recuerda y/u olvida es una construcción que se produce en un espacio relacional, donde una posición -lo que afirma, sostiene, interrogaes siempre una respuesta a otra posición (Reyes, 2009a).

En este marco, se realizó una investigación que tuvo por objetivo indagar en la forma dialógica -conflicto, consenso, alianza, entre otrasque se adopta entre distintas generaciones cuando se hace memoria de la dictadura militar, en el entendido que en dicho espacio relacional se reproducen y producen versiones del pasado (Reyes, 2009a).
Para ello, en una primera instancia se exploraron los contenidos generacionales respecto a dicho pasado a través de relatos de vida basados en narrativas (Reyes et al., 2013a) y fotografías que aportaron los mismos participantes (Reyes et al., 2013a). En un segundo momento, a través de grupos de discusión, se analizó la forma dialógica adoptada entre generaciones, es decir, la dialogía intergeneracional, siendo estos los resultados que se expondrán aquí.

La relevancia teórica y social de esta investigación radica en problematizar la noción de transmisión en los estudios de memoria, otorgando a la coexistencia y dialogía entre generaciones un rol central en la construcción de memorias. De este modo, se enfatiza que las distintas generaciones, tanto aquellas que vivieron, como aquellas que no vivieron directamente el pasado reciente, juegan un rol activo en el proceso de construcción y transmisión de memorias sobre el pasado.

\section{Generaciones y construcción de memorias}

Para Mannheim (1928) hablar de unidad generacional o generación, implica asumir que esta no se produce por el mero hecho biológico de haber nacido en un mismo tramo temporal, sino que es necesario una adhesión de los individuos a ciertos marcos histórico-sociales que dan cuenta de una forma propia de pensamiento, acción histórica y experiencia relevante. Por tanto, una nueva generación aludirá a "nuevos portadores de cultura" (Mannheim, 1928).

Es desde aquí que Aróstegui (2004) plantea que una generación "está verdaderamente presente" (p. 116) solo cuando sus concepciones son cuestionadas o incluso rechazadas por otra generación. Es decir, la constitución de una generación estará condicionada por el alumbramiento que otra generación realice de ella.

De acuerdo a lo anterior, cada generación introducirá nuevas concepciones a las ya instituidas, agregando Reyes (2009a) que dicho instituyente es posible por la presencia y dialogía intergeneracional, es decir por el espacio relacional que se configura entre generaciones. 
Schuman y Scott (1989) al estudiar las relaciones entre generación y memoria colectiva y al examinar el rol de las diferentes etapas de la vida en la producción de la memoria, refieren que el recuerdo de eventos políticos y cambios sociales importantes está estructurado según la edad, siendo la adolescencia y la adultez temprana los períodos primarios para el imprinting generacional. La generación será entonces construida mediante prácticas colectivas que responden a eventos socio-históricos experimentados en dichas etapas. Mientras más implicación genera un evento - por ejemplo, eventos traumáticos como el golpe de Estado en Chile-, los sujetos se verán más llamados a compartirlo socialmente y recordarlo.

\section{Dialogía intergeneracional: una} aproximación a la transmisión de memorias

Como se señaló anteriormente, qué recordar y qué olvidar son preguntas fundamentales para una sociedad que debe enfrentar un pasado de violencia política, reflejándose en ellas la preocupación por la 'herencia' hacia las nuevas generaciones. En el caso de los estudios de memoria en Chile, dicha preocupación ha sido abordada principalmente desde los llamados "emprendedores de memoria" (Jelin, 2002), focalizando en las acciones estratégicas que generan para desarrollar una política activa respecto al sentido del pasado que pretenden legar (Reyes, 2009b). Se torna así fundamental abordar preguntas como iquiénes se constituyen en emprendedores de la memoria?, ¿qué memoria es aquella que buscan transmitir?, iqué realzan y qué olvidan del pasado? Sin embargo, uno de los efectos que se genera con interrogantes de este tipo es marginar aquellas referidas al rol que cumplen en la transmisión aquellos que no vivieron directamente el pasado, así como al espacio relacional y dialógico que implica el acto de hacer memoria.

Asumiendo que la memoria del pasado no es una propiedad de unos que luego es trasferida a otros, sino más bien una construcción que se realiza en un espacio intersubjetivo, es que inspirados en Bajtín (1989), se propone la noción de dialogía intergeneracional (Reyes, 2009a) para abordar la problemática de la transmisión y construcción de las memorias del pasado. Con dicha noción se enfatiza el espacio relacional y el tipo de relación -de conflicto, de apoyo, de aprendizaje, entre otros- que se produce entre generaciones al hacer memoria.

La dialogía apunta a un discurso vivo (Bajtín, 1989) que en la construcción de su objeto, siempre y en todas las circunstancias se encuentra con el discurso ajeno, del cual no puede prescindir. Así, "construimos nuestro discurso propio en referencia al discurso ajeno, entrelazado con este, en respuesta a él y en anticipación a sus futuras respuestas" (García, 2006, p. 53). De este modo, realzar el carácter dialógico que subyace al hacer memoria implica poner atención a la compleja red de palabras ajenas, posiciones, valoraciones y relaciones que hacen emerger y en cierto modo cristalizan la construcción del pasado. Es reconocer y enfatizar la diversidad, las diferencias, así como también los posibles conflictos y luchas que pueden producirse pues la dialogía, tal y como sostiene Rivero (2003), genera tensiones entre discursos y en las situaciones sociales en que emergen.

Desde esta perspectiva, cada vez que se ponga atención a la construcción de memorias desde lo generacional, habrá que atender no solo a la 'sucesión' o 'relevo generacional' -cuestión que ha predominado en los estudios realizados en los ámbitos de la filosofía, la sociología y psicología de las generaciones y la historia (Aróstegui, 2004)-, o a las "memorias generacionales" (Miszstal, 2003), sino también y aún más enfáticamente, a la dialogía intergeneracional, comprendiendo cada recuerdo como una síntesis de las tensiones, conflictos y/o acuerdos entre las posiciones sostenidas por distintas generaciones. Para focalizar en ello es necesario considerar las generaciones que se articulan al recordar, así como el tipo de relación que se establece entre ellas.

\section{La transmisión en los estudios de memoria en Chile}

La preocupación por la transmisión de las memorias del pasado reciente de Chile se ha intensificado en la última década, focalizándose principalmente en el estudio de los "vehículos de memoria" (Jelin 
\& Langland, 2003), como los lugares de memoria (Veneros \& Toledo, 2009; Piper \& Hevia, 2012), la enseñanza-aprendizaje de la historia de Chile en las escuelas (Reyes, 2004; Toledo \& Magendzo, 2013), las conmemoraciones (Raposo, 2012), los “archivos orales" (Fernández et al., 2012), el rol de la Iglesia Católica (Reyes, 2004), entre otros. Asimismo, recientemente se ha introducido una lógica generacional en investigaciones sobre la memoria de la dictadura (Haye et al., 2009; Guichard \& Henríquez, 2011; Arnoso, Cárdenas, \& Páez, 2012; Carvacho et al., 2013).

Si bien estos estudios consideran en el análisis tanto a los "emprendedores de la memoria" (Jelin 2002), como a quienes 'reciben' activamente las narraciones del pasado, es marginal el abordaje dialógico entre generaciones. Uno de los estudios que ha puesto atención a ello es el de Reyes (2009a), planteándose como uno de sus hallazgos el conflicto que se produce en la relación intergeneracional al recordar el pasado, lo que se traduce en la ilegitimidad de narrarlo nítidamente, ya sea por parte de los 'testigos y/o protagonistas' como de los 'sucesores', lo que implica "silenciar el pasado, o bien hacerlo presente pero con mínimas palabras, ojala de aquellas que no provoquen mayores conflictos" (p. 311).

A partir de estos antecedentes se diseñó una investigación que tuvo por objetivo indagar en la dialogía intergeneracional que se produce cuando se hace memoria de la dictadura militar chilena, presentándose en este artículo los resultados obtenidos a partir de grupos de discusión y cuyo foco es dar cuenta de la forma dialógica que adoptan las distintas generaciones cuando en conjunto, hacen memoria de dicho pasado.

\section{Método}

\section{Diseño}

La investigación es de carácter cualitativo, orientada a reconstruir sentidos de situaciones y procesos vinculándolos a los contextos históricos particulares en que se producen (Vasilachis de Gialdino, 2009; Sandoval, 2013). Para abordar la complejidad de la dialogía intergeneracional en la construcción de memorias, se realizaron dos fases: la primera centró la atención en los contenidos generacionales respecto a la dictadura militar a nivel singular a través de relatos de vida (Reyes, et al., 2013), y la segunda focalizó el análisis en la forma dialógica que adoptan las distintas generaciones al conversar sobre la historia de la dictadura desde grupos de discusión. El procedimiento y los resultados de esta segunda fase son los que se expondrán a continuación.

\section{Instrumento}

La opción de realizar grupos de discusión (Ibáñez, 1992) se sustentó en que permite la convocatoria de distintas posiciones sociales a conversar sobre la historia de la dictadura. De este modo, los grupos producen un espacio interaccional propicio para el análisis de las generaciones que se constituyen a propósito de dicha conversación y de la forma dialógica que adoptan.

Como provocación para dar inicio a la conversación, se planteó a los participantes que imaginasen la posibilidad de guardar un audio sobre la historia de la dictadura militar en una cápsula del tiempo que sería abierta en cincuenta años más, preguntándoles, iqué les gustaría contar de dicha historia? Transcurridos 45 minutos a una hora y como segunda provocación, se les presentó un set de diez fotografías que fueron aportadas por los participantes de los relatos de vida con el fin de contar su propia historia de la dictadura a otras generaciones. La selección de dichas imágenes se realizó a partir de la recurrencia temática y de la heterogeneidad de posiciones ideológicas a las que aludían. A partir de ellas, se preguntó al grupo iqué fotografías elegirían para contar esta historia de la dictadura?, icuáles no elegirían?, icuáles faltan?

El criterio para definir el número de los grupos realizados -seis en total- fue el de la saturación estructural (Canales \& Peinado, 1995).

\section{Participantes}

Para la producción de los grupos de discusión se realizó un muestreo estructural (Canales, 2006) de acuerdo a las siguientes posiciones sociales: 
- Grupo etario: siguiendo los planteamientos de Mannheim (1928) así como los de Schuman y Scott (1989), se convocaron cuatro grupos etarios, en el entendido que podrían constituirse discursivamente en distintas generaciones: los mayores (más de 55 años) que cumplieron 18 años alrededor del golpe militar de 1973; los adultos (entre 40 a 55 años) que cumplieron 18 años alrededor del plebiscito de 1988 donde se decidía la continuidad de Augusto Pinochet al mando del gobierno; los adultos jóvenes (entre 30 a 40 años), que cumplieron 18 años alrededor de 1998, a diez años de dicho plebiscito; y los jóvenes (mayores de 23 años) que cumplieron 18 alrededor de la movilización de estudiantes secundarios del 2006.

- Posición ideológica: asumiendo su relevancia respecto a la construcción de memoria (Manzi, et al., 2004; Tocornal, 2008), se convocaron dos posiciones ideológicas -izquierda y derecha- al constituirse en indicadores relevantes en la cultura política chilena (Haye, et al., 2009).
- Nivel socioeconómico: se evaluó a partir de una estimación de los ingresos, considerando así tres niveles en función de la Encuesta $\mathrm{Ca}$ sen (Ministerio de Planificación, Gobierno de Chile, 2006): alto, medio y bajo.

- Territorio: considerando que la dictadura tuvo manifestaciones particulares según el territorio (Informe Comisión Nacional sobre Prisión Política y Tortura, 2004), se convocó a participantes provenientes de diferentes regiones del país: Norte (Antofagasta); Sur (Concepción); Central Costa (Valparaíso), y Región Metropolitana (Santiago).

Considerando el objetivo de dar cuenta de la dialogía intergeneracional en la construcción de memorias de la dictadura militar, se optó por convocar en cada grupo a personas que adscribieran a una misma posición ideológica y pertenecieran a un mismo territorio y nivel socioeconómico, pues facilitaría el despliegue de la narración respecto al pasado reciente. La única variante discursiva (Canales \& Peinado, 1995) que introdujo hetero-

TABLA 1

Distribución de participantes en grupos de discusión

\begin{tabular}{|c|c|c|c|c|c|c|c|c|}
\hline GD & NSE & PI & Ciudad & $\begin{array}{c}\text { GE } 1 \\
(>55 \text { años })\end{array}$ & $\begin{array}{c}\text { GE } 2 \\
(40 \text { a } 55 \text { años })\end{array}$ & $\begin{array}{c}\text { GE } 3 \text { (30 a } 40 \\
\text { años) }\end{array}$ & $\begin{array}{c}\text { GE } 4 \\
(24 \text { a } 30 \text { años })\end{array}$ & Total \\
\hline GD1 & Bajo & Derecha & Santiago & $\begin{array}{l}\mathrm{N}(76) \\
\mathrm{JC}(57)\end{array}$ & $\begin{array}{l}\mathrm{Ge}(54) \\
\mathrm{E}(50)\end{array}$ & $\begin{array}{l}\text { C(37) } \\
M P(35)\end{array}$ & $G(22)$ & 7 \\
\hline GD2 & Bajo & Izquierda & Antofagasta & $\begin{array}{l}\text { FER (64) } \\
\text { PA (57) }\end{array}$ & $G(40)$ & $\begin{array}{l}\mathrm{CR}(32) \\
\mathrm{CI}(30)\end{array}$ & $\begin{array}{c}\mathrm{E}(23) \\
\operatorname{FEL}(23)\end{array}$ & 7 \\
\hline GD3 & Medio & Derecha & Valparaíso & $\begin{array}{l}\mathrm{D}(60) \\
\mathrm{R}(58) \\
\mathrm{C}(57)\end{array}$ & $V(53)$ & $\mathrm{J}(33)$ & $\begin{array}{l}\mathrm{G}(30) \\
\mathrm{T}(29) \\
\mathrm{S}(28)\end{array}$ & 8 \\
\hline GD4 & Medio & Izquierda & Concepción & $\begin{array}{l}F(77) \\
P(58)\end{array}$ & $\begin{array}{l}\mathrm{I}(50) \\
\mathrm{R}(44) \\
\mathrm{T}(44)\end{array}$ & $\begin{array}{l}\mathrm{A}(38) \\
\mathrm{E}(35)\end{array}$ & $\begin{array}{l}S(25) \\
C(22)\end{array}$ & 9 \\
\hline GD5 & Alto & Derecha & Santiago & $\begin{array}{l}\mathrm{D}(63) \\
\mathrm{E}(56)\end{array}$ & $G(52)$ & $\begin{array}{l}\mathrm{L}(36) \\
\mathrm{J}(32)\end{array}$ & $\begin{array}{l}\mathrm{A}(26) \\
\mathrm{B}(21) \\
\mathrm{F}(21)\end{array}$ & 8 \\
\hline GD6 & Alto & Izquierda & Santiago & $\begin{array}{l}F(68) \\
A(62) \\
V(62) \\
R(57)\end{array}$ & L(49) & E(39) & $\begin{array}{l}\mathrm{B}(26) \\
\mathrm{P}(24) \\
\mathrm{J}(23)\end{array}$ & 9 \\
\hline Total & & & & 15 & 9 & 10 & 14 & 48 \\
\hline
\end{tabular}

Nota: GD: Grupo de Discusión; NSE: Nivel socioeconómico; PI: Posición ideológica; GE: Grupo Etario. Al interior de la tabla, las letras corresponden a las iniciales de los seudónimos de los participantes, mientras que los números entre paréntesis a sus edades.

Fuente: elaboración propia 
geneidad en cada grupo de discusión fue el tramo etario, permitiendo rastrear la configuración de generaciones y las formas dialógicas que adoptan en la conversación.

En total participaron 48 personas. Su distribución en función de las posiciones sociales se detalla en la Tabla 1.

\section{Procedimiento}

Los grupos de discusión fueron realizados entre los meses de junio y septiembre de 2012. El proceso de contacto y reclutamiento de los participantes se realizó por medio de informantes clave, invitándolos a conversar sobre 'cómo personas de diferentes generaciones recuerdan el período de la dictadura militar chilena'. Cada uno de los participantes firmó un consentimiento informado, el que enfatizaba la confidencialidad, el anonimato y la libertad de participar y de retirarse del estudio sin que esto significara ninguna consecuencia.

Los grupos fueron realizados en salas de distintas universidades, en el local de un edificio y en una sala de reuniones de un hotel, todas ellas propicias para este tipo de técnica, siendo la duración promedio de una hora y 45 minutos. Cada uno de los grupos fue moderado por una investigadora y observado por uno o dos integrantes del equipo de investigación. El registro se realizó por medio de audio, previa autorización de los participantes y luego fue transcrito literalmente para el análisis.

\section{Análisis de datos}

Las transcripciones fueron ingresadas al programa ATLAS.ti (Muhr, 2009), siendo la estrategia analítica: a) selección del corpus de análisis a partir del objetivo atingente a los grupos de discusión; b) codificación del corpus en base a criterios teóricos y emergentes de los propios datos; c) interconexión entre codificaciones que se agruparon en dos ejes transversales construidos a partir del objetivo trazado para los grupos de discusión que fueron analizados discursivamente (Íñiguez, 2003). El primer eje apunta a las generaciones discursivas que se constitu- yen en las conversaciones -idesde qué generación se enuncia el recuerdo?, ihacia qué generaciones va dirigida dicha enunciación?-, mientras que el segundo eje alude a la forma dialógica que adoptan dichas generaciones, es decir al tipo de relación que establecen cuando hacen memoria sobre la dictadura militar-de conflicto, de apoyo, de diálogo, de aprendizaje, entre otros-.

\section{Resultados}

A continuación se presentan los dos ejes analíticos que permiten dar cuenta de la dialogía intergeneracional que se produce al hacer memoria de la dictadura militar chilena. En primer lugar, la constitución de generaciones discursivas, donde la alteridad de referencia y relevancia para configurar la narración del pasado reciente es el adversario político. En segundo lugar, la forma dialógica que adoptan las generaciones cuando hacen conjuntamente memoria, siendo el debate la forma que predomina cuando están adscritas a una misma tendencia ideológica.

\section{Generaciones discursivas}

A diferencia de lo que ocurre desde los relatos de vida donde se constituyeron cuatro generaciones a partir de los contenidos que daban forma a las memorias de la dictadura militar, tanto en términos discursivos (Reyes, et al., 2013a) como en términos visuales (Reyes, et al., 2013a), en los grupos de discusión donde está efectivamente presente otro que puede adherir, cuestionar o bien rechazar lo planteado, se constituyen tres: la generación protagonista del pasado, la generación protagonista del presente e intermitentemente, la generación de la zona gris. Dichas generaciones en tanto posiciones discursivas, surgen a propósito de un campo temático (Haye, Carvacho, \& Larraín, 2011) que es el de las memorias de la dictadura militar, instalando consigo un eje articulador respecto a cómo posicionarse y argumentar cuando el objeto de conversación es el pasado reciente: la vivencia o no vivencia en primera persona de dicho pasado. Así, no solo resulta llamativo, sino también condicionante de la conver- 
sación el cómo los participantes suelen presentarse frente a los otros:

Mi nombre es Martina, tengo 35 años y bueno, yo sé por cosas que me han contado, por ejemplo mi mamá que ella vivió en ese tiempo, pero yo en realidad soy del 77, así que no viví como la época a plenitud ni estuve en todo [...] la época del 73 yo no la viví, yo estuve con el 77, del 80 casi. (GD1, NSB, Derecha) ${ }^{1}$

Eh, yo, quisiera hablar un poco de lo que yo viví a modo personal de lo que fueron los tiempos de dictadura. (GD4, NSM, Izquierda)

[...] entonces, no viví directamente ninguna parte de este proceso, solo puedo saber a través de [...] de las historias, de lo que me dicen terceros, pero también de que lo veo reflejado en la actitud de las personas, por ejemplo en mi universidad. (GD3, NSA, Derecha).

El haber vivido la dictadura militar en primera persona, otorga legitimidad ante los otros para narrar el pasado. Los 'yo viví', 'ella vivió', 'no viví directamente' de los participantes apuntan a instalarlos en la conversación desde una historia personal e individual que, como toda historia singular, tiene la particularidad de ser irrebatible en espacios públicos y cotidianos, salvo que el encuentro sea con otro testigo o protagonista que, dada su propia experiencia, puede contra argumentar lo sostenido (Reyes, Muñoz, \& Vázquez, 2013b). De esta manera, cuando se está en conversación con otros, donde la diferencia central es la edad en tanto contemporaneidad con la ocurrencia de un hecho histórico por el cual se ha convocado a conversar, el ser protagonista y testigo de lo acontecido se constituye en un recurso para sostener una particular versión del pasado y con ello, la constitución de particulares generaciones.

1 Se utilizarán viñetas extraídas de los grupos de discusión. En el paréntesis se identifica el número del grupo de discusión, el nivel socioeconómico (B: bajo; M: medio; A: alto) y la posición ideológica a la que pertenece. Los nombres de los participantes son seudónimos.

\section{La generación protagonista del pasado}

Las enunciaciones realizadas principalmente por quienes pertenecen al grupo etario 1 (en adelante GE1), suelen acudir a aseveraciones del tipo 'yo lo viví' -por ejemplo: "todo lo que dije yo es verdad, porque lo viví" (GD1, NSB, Derecha)-, y a marcar los tiempos e inflexiones de la conversación, siendo ilustrativo de ello cómo en cinco de los seis grupos de discusión, quien toma la palabra luego de la primera provocación para conversar es alguien del GE1. De este modo, se refuerza lo planteado anteriormente: que la legitimidad de la palabra para hacer memoria del pasado reciente pertenece principalmente a quienes vivieron en primera persona la dictadura militar.

Ahora bien, el 'yo lo viví', suele ir acompañado de una inscripción socio-histórica, aludiendo al clima político, social y económico que caracterizaba a esos tiempos. Por tanto, es una experiencia singular que cobra sentido y significado desde el acontecer social.

R: Yo contaría una historia, donde el protagonista, lamentablemente, era, es el miedo, y diría que tener, vivir en un país de miedo, eh no vale mucho la pena, es como un tiempo perdido, porque para mí la dictadura, en el período de, después del golpe, yo tuve mucho miedo, mucho, mucho miedo, o sea, porque te mataban a tu vecino, a tu hermana mayor, a tu papá, y ese, ese protagonista del miedo, yo creo que no es bueno para crecer como país ni para crecer como persona y, yo contaría una historia, donde terminaría como corolario así, donde por supuesto, esto ojalá [alguien tose], no pase jamás.

Moderadora: Aha.

R: Esa sería una historia que yo diría.

A: Yo pondría historia como desde antes, antes había vida de barrio, un salir y vecinos, no había desconfianza, no había esta cosa tan aislada de ser uno no más, sin importarte el otro, éramos un país distinto. (GD6, NSA, Izquierda)

Yo no quiero esquivar digamos lo que soy, yo soy, eh, hijo de una familia bien tradicional, eh agricultores, en ese tiempo éramos momios [término usado en Chile durante las décadas de 1960 y 1970 para 
referirse a personas de orientación política de derecha], [...] tuve un cargo público en la época, no sé si ustedes se acuerdan, de las protestas, cacerolazos, las velatones, unas donde prendían velas y todo eso. Claro pa' la cápsula del tiempo yo pondría en contexto, como bien dice "A", las causas [del golpe], ah, $\mathrm{y}$, si bien, claro, hubieron excesos, estoy totalmente de acuerdo además, hubieron excesos, no estoy justificando digamos violaciones graves a los Derechos Humanos, ah, pero, el contexto digamos era bien otro. (GD3, NSA, Derecha)

"Vivir en un país de miedo", "éramos un país distinto", "en ese tiempo éramos momios”, son formas de enunciar que enfatizan una temporalidad -pasado reciente- vivida en forma colectiva. A pesar de las diferencias ideológicas que se evidencian en las viñetas, hay un 'nosotros' que logra articularse a propósito de experiencias históricas vivenciadas cotidianamente, justamente desde personas inscritas en un mismo tramo etario. En este sentido, siguiendo el planteamiento de Mannheim (1928), discursivamente se conforma y delimita una generación, que hemos denominado protagonista del pasado.

Ser protagonista alude a constituirse en personaje principal de la acción en una historia. Tal como se evidencia en las viñetas, es el mismo sujeto que realiza la enunciación el que se sostiene como eje de la acción al narrar el pasado en función de su propia experiencia. En este sentido y al igual que lo que se produce en los relatos de vida (Reyes, et al., 2013a) la historia personal se entrecruza fuertemente con la historia social, en particular con aquella relativa a la dictadura militar.

Este protagonismo se da aún más fuertemente cuando los participantes se posicionan en uno de los polos que estuvo directamente involucrado en el conflicto político del pasado reciente.

P: Entonces si me preguntan iqué pasó durante la dictadura? Yo la viví militando en una organización política con muchos costos humanos, eh, de esos mil compañeros yo tengo que haber conocido unos 100 por lo menos. En diferentes condiciones, en enfrentamientos, en las torturas, en las cárceles.
I: En el exilio.

P: En el exilio también. Hay gente que murió de pena. Gente que nunca pudo volver a Chile [...] Entonces el dolor fue permanente. Entonces no quedaba otra opción que luchar con todas las ganas para terminar con esta situación. (GD4, NSM, Izquierda)

Yo en ese tiempo entré a la, pertenecí a un grupo de choque de un partido [...] participé en marchas, participé en tomas, iya?, tomas contra Allende. Y a los pobres pacos les llegaban las piedras igual, si en cualquier gobierno que esté a los pobres pacos les llega igual. Y se produjo el pronunciamiento militar. Donde yo creo que la gran mayoría de la gente quería eso. Y hablando de la mayoría, estamos hablando de más o menos que el $80 \%$ de la población estaba de acuerdo con el gobierno militar. Con el golpe de Estado, con sacar a Allende. (GD5, NSA, Derecha)

Lo anterior muestra que la generación protagonista del pasado lejos está de ser una colectividad homogénea y compacta en cuanto a la posición ideológica respecto al pasado reciente. Al contrario, tal y como se evidencia en las distintas viñetas, se constituye desde la heterogeneidad e incluso desde la polarización ideológica.

\section{La generación protagonista del presente}

"Yo sé por cosas que me han contado", "no viví directamente ninguna parte de este proceso", son algunas de las enunciaciones que suelen anteceder a las afirmaciones realizadas por jóvenes entre 24 y 30 años (GE4) en la conversación sobre la historia de la dictadura militar chilena. Para narrar el pasado reciente de Chile en un contexto donde hay otros cercanos a la ladera ideológica, pero distintos en términos etarios, tal como sugieren los discursos en los grupos, se requiere posicionarse en función de la vivencia o no en primera persona de lo 'ya acontecido'.

Sin embargo, esta no es la única confluencia en este grupo etario, ya que además logran constituirse como una generación discursiva, la protagonista del presente, aunque de un modo distinto a como lo hace la generación protagonista del pasado. 
Yo soy Gabriel [...] y yo soy de la generación más joven. (GD1, NSB, Derecha)

Soy Bruno, estudio economía, nacido en democracia [risas] y qué más, también vengo de familia militar. (GD3, NSA, Derecha)

Mi nombre es Javiera, soy estudiante de derecho, tengo 23 años, eh soy nieta de exiliado político, ehm militante del partido comunista en ese momento, en ese tiempo [...] Son cargas y son dolores que se arrastran intergeneracionalmente, o sea no es solamente lo que vivieron tus abuelos o tus padres, sino que tú lo vives todos los días, lo ves en tu casa lo ves, lo ves en tu universidad, lo ves en tus amigos y es algo que no se olvida (GD6, NSA, Izquierda).

$\mathrm{Al}$ ser un eje fundamental la vivencia directa del pasado reciente para recordar en el espacio público y cotidiano, tal y como se desprende de los discursos en los grupos de discusión, los jóvenes realizan un particular movimiento que los configura en 'nosotros', siendo este el de distinguirse, pero a la vez establecer una particular relación con la generación protagonista del pasado. Así por ejemplo, se habla de una 'generación más joven'; o se inscribe el nacimiento en un período sociohistórico distinto y sucesivo al de la dictadura -"nacido en democracia" -; o bien se establece una relación filial desde la cual se produce un posicionamiento -"soy nieta de".

Este posicionamiento generacional se ve fuertemente potenciado por las movilizaciones estudiantiles de los años 2006 y $2011^{2}$, acontecimientos socio-históricos que les permite reconocerse como parte de un mismo colectivo, distinto al de la generación protagonista del pasado.

Y yo tampoco lo viví, no tengo familiares directos y quizás alguna gente consideraría como que no tengo derecho a opinar pero creo que es nuestra

2 En los años 2006 y 2011, ocurrieron importantes y masivas movilizaciones a lo largo de todo Chile, principalmente de estudiantes secundarios y de estudiantes secundarios y universitarios, reivindicando una educación pública de calidad, gratuita e igualitaria. historia y la historia de todos los chilenos que nos está pesando ahora. Que es la historia que nos pesó a nosotros como estudiantes el año pasado cuando, cuando salíamos a marchar. (GD4, NSM, Izquierda)

Denominamos a esta generación como protagonista del presente porque se sitúan y se constituyen como actores de su propio presente, estableciendo a través de sus acciones y posturas una distinción con los 'otros' -padres, abuelos-. Como señala uno de los jóvenes, instalan su "propio punto de vista". De esta manera, es una generación que no se constituye como mero 'receptor' o 'sucesor' del legado del pasado reciente de Chile, en una lógica de transmisión oral de lo sucedido, sino más bien como colectivo que 'genera' nuevos discursos y prácticas, siendo las memorias del pasado un referente para su acción en el presente.

\section{La generación de la zona gris}

$\mathrm{Al}$ focalizar en lo señalado por personas entre 30 a 55 años (GE2 y GE3) se repite una constante: situarse respecto a la vivencia directa o no de la dictadura militar.

[...] ese proceso [refiriendo a la Dictadura] podrían tratar digamos de cómo lo vivieron ellos también y nosotros podríamos ver lo que a nosotros la apreciación que nosotros tenemos ya con distintas vistas que nos han dado nuestros padres nuestros tíos nuestras personas más, más adultas pero directamente nosotros no tuvimos sino que nosotros tomamos la parte final, la parte final [...] pero la parte cuando estuvo todo el problema no directamente nosotros no [...] yo la viví como cabro chico [...] yo veía a los militares en la calle y para mí era un juego. (GD2, NSB, Izquierda)

Yo la verdad es que tengo 37 años, yo nací el 74, así que no viví, ósea mi tema más que nada es lo que me habló, me dijo el padre [...] la verdad es que también viví situaciones en el colegio, de protestas, de tomas, de toques de queda [...] yo no viví situaciones muy complejas. (GD1, NSB, Derecha) 


\section{María José Reyes Andreani, Marcela Cornejo Cancino, María Angélica Cruz Contreras, Constanza Carrillo, Patricio Caviedes}

Tal como evidencian las viñetas, los participantes se sitúan de un modo distinto respecto a las generaciones descritas anteriormente. Por una parte, manifiestan no haber vivido directamente la época de dictadura, teniendo conocimiento de ella por historias contadas por otros - padres, abuelos, tíos-, mientras que por otra, explicitan haberla vivido en su infancia. Si bien esta particularidad produce condiciones para la constitución de una generación, esta no logra configurarse de forma consistente y persistente en los discursos y por tanto, distinguirse respecto a los 'otros', en especial ante la generación protagonista del pasado. Sus enunciaciones más que 'generar' nuevos discursos, tienden a apoyar y/o a contraponerse a posturas defendidas por las generaciones protagonistas, tanto del pasado como del presente.

En ocasiones, se produce un auto reconocimiento de los participantes respecto a la inscripción socio-histórica y a la sensibilidad común que ello implica para posicionase y accionar en el mundo, aunque solo es saliente en aquellos que se inscriben en una posición ideológica de izquierda: la 'generación de los $80^{\prime}$ es nombrada y distinguida respecto a otras generaciones.

Mi generación fue la de los 80 ' entonces estuve muy involucrada en lo que fueron los, los acontecimientos, yo digo hoy históricos, que yo tengo de esa fecha.[...] En esos años nosotros, eh, nuestro sentir que teníamos era compartir pero a la vez era, era el poder trabajar por lo social [...] Eh, muy involucrado con lo que eran las manifestaciones, los trabajos voluntarios, y en el saber, en el querer saber lo que le estaba pasando a cada uno de nuestros vecinos, amigos. (GD4, NSM, Izquierda)

El hecho que en momentos emerja claramente una unidad generacional -como en el caso de la viñeta-y que luego se diluya en la conversación con otros generacionales; que en ocasiones hablen con propiedad del pasado por haber vivido en primera persona la dictadura, pero que al poco andar se abstengan de posicionarse pues no fueron protagonistas de esa historia, son dos razones que nos permiten denominar a esta generación como de la zona gris. 'Zona' pues en algunos momentos se logran constituir límites que permiten distinguirla de las otras generaciones, por ejemplo cuando se afirma que se ha vivido la época de dictadura -distinción que opera respecto a la generación protagonista del presente-, y que ha sido una vivencia desde la infancia -distinción que opera respecto a la generación protagonista del pasado-. Y 'gris', porque dichos límites son difusos, no solo porque se constituyen en contados momentos de la conversación, sino también porque no logran establecer una diferencia respecto a la generación de discursos, es más, estos se diluyen e incluso en momentos desaparecen con el decir de las otras generaciones.

\section{La marca de lo ideológico: el debate como dialogía intergeneracional}

\section{La polarización en escena: 'ellos' y 'nosotros'}

Cuando se está en conversación sobre qué historia de la dictadura les gustaría fuera contada en cincuenta años más, entre quienes adscriben a una misma tendencia política y pertenecen a un mismo nivel socioeconómico pero a diferentes generaciones, lo primero que resalta es la construcción de una narración que adquiere una impronta fuertemente ideológica. De esta manera, es claramente distinguible lo que tradicionalmente en el contexto chileno se ha entendido como un relato de izquierda y un relato de derecha cuando la dictadura es el centro de la discusión.

Pero era un caos o eran ellos o el país, así de simple, no había otra alternativa, por eso es que ocurrió lo que ocurrió, y por eso es que el General hizo lo que hizo, o sea no había otra alternativa, no puedes, oye te damos la oportunidad tal vez conversemos, dialoguemos, veamos cómo sacar este cuento [...] y no ocurrió, porque ellos estaban preparando, el señor Castro se quedó aquí como cuatro meses [...] cuatro meses [...] instrucción militar, o sea, igual a lo que ocurre hoy en Cuba, y nos libramos, nos libramos. (GD1, NSB, Derecha)

Bueno uno tiene que vivir la historia desde un punto de vista particular que es la que, desde el punto de 
vista que le toco vivirla. A mi esta historia me tocó vivirla con un golpe de Estado a la edad de 19 años. A la edad de 16 viví el triunfo de Salvador Allende. Eso abrió a la juventud [...] un mundo de ilusión y de posibilidades. Nosotros queríamos cambiar el mundo lo antes posible dada la injusticia en que vivíamos, dada la pobreza que vivía la gente en un país tremendamente rico en recursos naturales. $\mathrm{O}$ sea no merecíamos vivir, de acuerdo a las condiciones materiales que tenía este país, de esa forma [...] entonces viví el golpe de Estado como el fin de un sueño [...] hablar de la dictadura es hablar de un golpe a la vida, un golpe moral a la integridad a las personas. Aquí no solo se cambió al país, aquí se cometió un crimen contra la humanidad. (GD4, NSM, Izquierda)

En las enunciaciones llama la atención no solo cómo apelan a dos versiones opuestas y contrarias respecto al pasado reciente, sino también al establecimiento de un ellos -el adversario político- y un nosotros -el aliado político- en una relación de polarización. El 'otro' en un contexto de 'guerra' - primera viñeta- o bien de dictadura -segunda viñeta- opera como un 'enemigo' ante el cual hay que defenderse y/o arremeter. En este sentido, afirmaciones como "eran ellos o el país" o "hablar de la dictadura es hablar de un golpe a la vida", interpelan política y éticamente de forma directa al ellos, es decir al adversario, por medio de dos vías.

La primera, a través de la interpretación y valoración que se le otorga a lo acontecido en el pasado reciente -bien una "liberación", bien un "crimen contra la humanidad", según sea la posición política adscrita-, generando como efecto no solo la legitimación de la propia versión, sino también la imposibilidad de cuestionarla -"no había otra alternativa, por eso ocurrió lo que ocurrió", o "nosotros queríamos cambiar el mundo lo antes posible dada la injusticia en que vivíamos"-.

La segunda a través del lugar en el que es situado el adversario, sea como una suerte de 'guerrillero' al haber estado en "instrucción militar", o bien como "criminal" al ser responsable de las violaciones a los derechos humanos. Sin embargo, a pesar de lo provocativo de la interpelación, en ninguno de los grupos se produce una contra argumentación o un cuestionamiento a lo planteado. Al contrario, se colabora y coopera en la construcción de la versión del pasado, introduciendo nuevos antecedentes, ejemplos y/o argumentaciones.

Yo siempre he pensado, y me da un poco de lata que la izquierda se llena la boca y se atribuye que son los paladines que recuperaron la democracia, y a la primera demuestran que es todo lo contrario. Y a nosotros nos tratan de fascistas, que en verdad no tienen idea de lo que es el fascismo, pero nos tratan de fascistas a los de derecha. Y, y, y nosotros somos, ellos hacen homenajes a Allende, a los hermanos Vergara y Toledo, y nadie les dice nada, y hagan sus cuestiones, y rompan la mitad de Santiago, pero nadie les dice nada. Nosotros queremos ver un documental [sobre Pinochet] nos van a agredir. (GD5, NSA, Derecha)

Moderadora: ¿Qué historias acerca de la dictadura les gustaría a ustedes que ahí [cápsula del tiempo] se escucharan?

J: Espero que las más horribles, de todo corazón espero que sean las más feas, las más horribles, para que a nadie nunca se le ocurra decir o pretender que la dictadura en Chile fue algo bueno, fue algo necesario, fue algo justificable, creo que si no señalamos la verdad como decía "R", si no hablamos de los horrores que se sufrieron, justificando siempre en el poder económico, en que seamos más, seamos más desarrollados, no importa por sobre quién pasemos, si es que no lo recordamos así, no vale la pena, no importaría. (GD6, NSA, Izquierda)

Cuando la conversación se da entre personas con una tendencia ideológica compartida, como es el caso de estos grupos de discusión, no solo se releva un 'ellos' y un 'nosotros', sino también el cómo la versión del pasado a través de la colaboración entre las distintas generaciones, se instala con certezas y mínimas fisuras. Lo anterior cobra sentido, pues el adversario político e incluso ético que se articula en el discurso, no está presente para contrarrestar lo aseverado. Al contrario, es el 'nosotros', en tanto 
aliados ideológicos, el que se constituye en la conversación entre las distintas generaciones.

\section{El debate como gestión de las diferencias}

El que predomine la colaboración y cooperación en la construcción del pasado entre las generaciones de una misma posición ideológica, no implica que no se produzcan diferencias e incluso tensiones en la conversación. Cómo narrar el pasado, cómo narrar el presente en función del pasado y el problema de la transmisión del pasado, serán causas de estas tensiones.

Cuando el foco es la historia de la dictadura que se quisiera contar, el cómo nombrar y calificar a personajes y acontecimientos del pasado, así como el qué relevar en dicho relato, pasan a ser operaciones de importancia, generando momentos de tensión entre los participantes de los grupos.

G: iqué sucede en el 73? golpe de Estado, ahora del 73 pa' delante uno podría empezar a criticar todas las cosas, yo soy derechista pero yo me acuerdo bien. Pinochet hizo lo que tenía que hacer pero las cosas se le salieron de las manos [...]

JC: pero "G" escúchame, pero mira todos critican al General Pinochet porque hizo esto y esto otro, pero el General Pinochet iqué era lo que era? era un General del ejército de la República, era un general preparado para la guerra [...] por lo tanto actuó en su forma, en su esencia, así actuó, entonces icómo critican? Si a nosotros nos ataca Perú, Bolivia, qué sé yo, la misma Argentina que es expansiva, icómo queremos nosotros que los generales actúen? Que nos defiendan poh, así actuó el General Pinochet, defendió a Chile.

G: El golpe se venía venir, eso está claro, por supuesto. (GD1, NSB, Derecha)

La tensión que se produce en este caso al relevar 'críticas' a lo ocurrido luego del 'golpe', se evidencia de inmediato con la arremetida de JC. Sin embargo, es una tensión que no llega a constituirse en conflicto, en la medida que $\mathrm{G}$ de inmediato apoya lo enunciado por JC -"eso está claro, por supuesto"-, dejando a un lado la diferencia y con ello distendiendo la conversación.

Otra de las situaciones donde se producen diferencias se da respecto a cómo narrar el presente en función del pasado, en particular el 'peso' de la dictadura en el acontecer actual.

E: no se acabó la dictadura y se acabó el periodo [...] quedaron secuelas igual quedaron, fueron quedando consecuencias igual, fueron quedando hechos que ocurrieron en ese periodo, y eso es lo que la gente eeh más jóvenes que a pesar que no hayan vivido esa parte de la historia viven lo que son las consecuencias $[\ldots]$

CI: yo respeto a las personas que lo vivieron, los que no lo vivieron creo que, yo no le puedo echar la culpa a la sociedad, no le puedo echar la culpa al golpe militar [...] no puedo culpar de todo lo que hay al régimen militar. (GD2, NSB, Izquierda)

Sin embargo, dichas diferencias no logran constituirse en conflictos, pues luego que CI deslegitima el argumento de $\mathrm{E}$ a través de la distinción entre quién 'vivió y no vivió' la dictadura, estas se diluyen en la conversación.

Finalmente se producen diferencias cuando se aborda el problema sobre la transmisión de lo vivido. ¿Corresponde o no transmitir el pasado reciente a las nuevas generaciones?, iqué transmitir?, iqué rol deben asumir los jóvenes ante un pasado no vivido?

F: A mí, o sea, como persona nacida en democracia, encuentro que lo mejor que se puede hacer eh, es abandonar eso, y yo, yo me considero de derecha, pero me considero también que ese legado, ya no me corresponde a mí defenderlo ni también tratar de atacarlo para intentar avanzar, es la única forma, el único lastre grande que tenemos. En que hay mucha gente que le gusta seguir con eso, con ese tema, pero a mí me da la impresión que no son, que son los de menos muchas veces. (GD5, NSA, Derecha)

Sin embargo, al igual que en las otras situaciones, dichas diferencias no lograrán generar conflic- 
to. Las diferencias y/o tensiones puestas en escena son enfrentadas a través de distintas tácticas discursivas que tienen como eje central el haber o no vivido en primera persona el tiempo de dictadura militar. Es decir, el protagonismo respecto al pasado. Así, aludir a la historia personal (se apela a la familia o a la propia experiencia para sostener la posición); explicitar la diferencia entre quienes vivieron directamente la dictadura y quienes no; o bien la retirada de la palabra (quedarse en silencio luego de haber instalado la diferencia en la conversación), usualmente por parte de la generación protagonista del presente, serán las tácticas mayormente desplegadas.

Si bien las diferencias, como las tácticas para enfrentarlas, no producen conflicto entre las generaciones, es decir que no despliegan una lucha contra la posición que fragiliza y amenaza la propia (Reyes, et al., 2013b), sí generan debate al producir un intercambio de posiciones respecto al pasado, direccionando el esfuerzo a aclarar e inscribir en la conversación el punto de vista particular. Un debate por cierto, que tiene por efecto potenciar una versión unívoca del pasado.

La forma dialógica del debate se sustenta desde distintos posicionamientos generacionales, en particular entre la generación protagonista del pasado y la generación protagonista del presente, así como de la homogeneidad ideológica al interior del grupo de discusión convocado. De este modo, el 'otro generacional' se constituye en un 'aliado' que colabora en la configuración de una particular memoria del pasado, mientras que el 'otro ideológico', sea cual fuese su posición generacional, en un adversario situado en la antípoda.

\section{Discusión}

Si se asume por una parte a la memoria como una construcción contingente, contextual e inacabada (Vázquez, 2001) y por otra, la coexistencia de distintas generaciones en el presente (Aróstegui, 2004), cobra sentido la pregunta sobre la dialogía intergeneracional, es decir sobre el espacio relacional y el tipo de relación que se produce entre generaciones cuando se hace memoria de un pasado de violencia política como el acontecido en Chile, pues en ello se juega, como dirá Birulés (1999), la responsabilidad social respecto a "lo que asumimos de lo que ya no está presente y de lo que todavía no es (y acaso nunca será)" (p. 146).

A pesar de haber convocado en cada grupo de discusión a cuatro grupos etarios para conversar sobre la historia de la dictadura en Chile, uno de los primeros hallazgos es cómo discursivamente se constituyen solo tres generaciones. Así se configura por una parte, la generación protagonista del pasado, que desde las claves de Lenz (2011) sería una generación arqueológica, pues la experiencia socio-histórica se constituye en un tiempo colectivo que permite generar horizontes de experiencia e interpretación compartidos, transformando lo acontecido en un referente de la acción presente y futura. Por otra parte, se evidencia la generación protagonista del presente, constituida principalmente desde un posicionamiento generacional genealógico (Lenz, 2011), pues las experiencias desde las cuales los jóvenes narran el pasado y se reconocen en un 'nosotros' dan cuenta de un antecedente - por ejemplo 'la dictadura'- y de una sucesión - por ejemplo 'los más viejos'-. Finalmente, se configura de forma intermitente la generación de la zona gris, la que no logra establecer límites y discursos claramente distintivos respecto a las otras generaciones.

Estas generaciones, en particular la protagonista del pasado con la protagonista del presente y de modo intermitente la generación de la zona gris, establecen la forma dialógica del debate que es posible sintetizar del siguiente modo: las diferencias que se presentan entre las generaciones al conversar sobre la dictadura militar, ya sea respecto a cómo narrarla, cómo narrar el presente en función del pasado, así como respecto al problema de la transmisión, no logran generar un conflicto que implique la marginación total de la posición planteada. Al contrario, las diferencias logran re-articularse en la conversación de modo tal que terminan potenciando una particular versión del pasado, que siguiendo a Potter (1998), adopta la retórica de un hecho, es decir, de un acontecimiento neutral ocurrido con independencia del participante.

Lo anterior da cuenta de la relevancia de lo ideológico no solo al hacer memoria del pasado 
reciente -es decir que dependiendo de la posición ideológica, será el tipo de versión que se configura del pasado-, sino también a la forma dialógica que se adopta entre las generaciones cuando ello ocurre. Una investigación anterior realizada en Chile (Reyes, et al., 2013b) evidenció cómo cuando se estaba en conversación directa con un adversario político no era posible plantear una versión del pasado al modo de un hecho, pues implicaba una transgresión a la convivencia cotidiana, siendo la dialogía intergeneracional predominante la del conflicto respecto a la legitimidad de narrar el pasado (Reyes, 2009b), generándose como consecuencia la imposibilidad de articular una versión del pasado con claras coordenadas históricas y políticas. Sin embargo, tal y como dan cuenta las conversaciones de los grupos de discusión de esta investigación, cuando el adversario político no está presente materialmente sino virtualmente y cuando los otros generacionales presentes son situados como aliados, la construcción de un hecho es lo que prevalecerá al hacer memoria de la dictadura, mientras que el debate será la dialogía predominante entre las generaciones.

Los resultados expuestos dan cuenta de cuestiones de relevancia a la hora de pensar en las memorias que se construyen en un contexto de post dictadura en Chile. En primer lugar, el debate como forma dialógica intergeneracional habla de la dificultad no solo de hablar, sino de expresar públicamente diferencias respecto al pasado reciente, tal y como lo han referido los relatos de vida de esta misma investigación (Reyes, et al., 2013a), así como otros estudios (Reyes, et al., 2013b; Arnoso, et al., 2012). Las pocas instancias de conversación sobre el pasado, a pesar incluso de los esfuerzos político-institucionales por instalarlas, por ejemplo a través del Museo de la Memoria y de los Derechos Humanos en 2010, está implicando que se difumine una de las funciones de la memoria: la de constituirse en un escenario de enunciación política (Vázquez, 2002). Incluso cuando se conversa inter-generacionalmente sobre dicho pasado con aliados ideológicos, las diferencias que se plantean, más que cuestionar, interrogar e introducir matices a lo afirmado, tienden a cooperar en la configuración de una versión que si bien alude a coordenadas políticas e incluso históricas, no propicia necesariamente la reflexión e interrogación respecto al pasado, ni tampoco sobre el presente y el futuro.

En segundo lugar, el debate entre dos generaciones que se articulan como protagonistas, bien del pasado, bien del presente, evidencia cómo la memoria del pasado reciente, habiéndose cumplido ya en Chile cuarenta años del golpe de Estado, sigue implicando a los/as chilenos/as, constituyéndose como referente para las acciones presentes. Sin embargo y aquí algunas interrogaciones, el que una de las generaciones se constituya en protagonista del pasado al haberlo vivido en primera persona, isupondría que son sujetos en términos políticos solo desde la nostalgia, restándoles potencia como sujetos de los conflictos del presente?, y el que los jóvenes actuales se constituyan como generación protagonista del presente en clave genealógica, ino les resta posibilidad de ser sujetos en el trabajo de la memoria?, ino los deja como los únicos responsables del presente?

Considerando que la clave generacional se está introduciendo en los estudios de memoria, es de relevancia que no solo apunte a la 'memoria generacional', sino también al espacio relacional y tipo de relación que se establece entre generaciones, pues es en dicha dialogía donde se producen las memorias del pasado para el futuro. Focalizar en la forma relacional entre generaciones nos dará pistas de las tensiones y obstáculos, pero también de los recursos que se traman cuando aquellas dan forma y lugar al pasado en el presente.

\section{Referencias}

Aguilar, P. (1996). Memoria y olvido de la Guerra Civil española. Madrid: Alianza.

Aguilar, P. (2008). Políticas de la memoria y memorias de la política. El caso español en perspectiva comparada. Madrid: Alianza.

Arnoso, M., Cárdenas, M., \& Páez, D. (2012). Diferencias intergeneracionales en la mirada hacia el pasado represivo chileno. Psicología Política, 45, 7-26

Aróstegui, J. (2004). La historia vivida sobre la historia del presente. Madrid: Alianza. 
Bajtín, M. (1989). Teoría y estética de la novela. Trabajos de investigación. Madrid: Taurus.

Birulés, F. (1999). Responsabilidad política. Reflexiones en torno a la acción y la memoria. En M. Cruz, \& R. Aramayo (Eds.), El reparto de la acción. Ensayos en torno a la responsabilidad, (pp. 141-52). Madrid: Trotta.

Canales, M., \& Peinado, A. (1995). Grupos de discusión. En J.M. Delgado, \& J. Gutiérrez (Coords.). Métodos y técnicas cualitativas de investigación en ciencias sociales (pp. 288-316). Madrid: Síntesis.

Canales, M. (2006). El grupo de discusión y el grupo focal. En M. Canales (Ed.). Metodologías de investigación social. Introducción a los oficios (pp. 265-287). Santiago: LOM.

Carvacho, H., Manzi, J., Haye, A., González, R., \& Cornejo, M. (2013). Consenso y disenso en la memoria histórica y en las actitudes hacia la reparación en tres generaciones de chilenos. Psykhe, 22(2), 33-47. http://dx.doi.org/10.7764/psykhe.22.2.601

Cornejo, M., Reyes, M. J., Cruz, M. A., Villarroel, N., Vivanco, A., Cáceres, E., \& Rocha, C. (2013a.) Historias de la dictadura militar desde voces generacionales. Psykhe 22(2), 49-65. http://dx.doi. org/10.7764/psykhe.22.2.603

Cornejo, M., Morales, G., Kovalskys, J., \& Sharim, D. (2013b). La escucha de la tortura desde el Estado: la experiencia de los profesionales de la Comisión Nacional sobre Prisión Política y Tortura en Chile. Universitas Psychologica 12,(1), 271-284.

Comisión Nacional Sobre Prisión Política y Tortura (2004). Informe de la Comisión Nacional sobre Prisión Política y Tortura. Santiago, Chile: Autor. Disponible en http://www.bcn.cl/bibliodigital/ dhisto/lfs/Informe.pdf

Cruz, M. A. (2004). Iglesia, represión y memoria: El caso chileno. Buenos Aires: Siglo XXI.

García, J. (2006). Identidad y alteridad.. Acta Poética, 27(1), 45-61.

Guichard, E., \& Henríquez, G. (2011). Memoria histórica en Chile: una perspectiva intergeneracional desde Concepción. Reis: Revista Española de Investigaciones Sociológicas, 135, 3-26.

Fernández, C., Rivas, R., Rodríguez, R., Prudant, E., Videla, E., Hevia, E., Escobar, M., \& López, L. (2012). Archivo y memoria. La experiencia del ar- chivo oral de Villa Grimaldi. Santiago: Corporación Parque por la Paz Villa Grimaldi, Instituto de la Comunicación e Imagen, Universidad de Chile, Fundación Ford.

Halbwachs, M. (1925/1968). Los marcos sociales de la memoria. Barcelona: Anthropos.

Halbwachs, M. (1950). La memoria colectiva. Zaragoza: Prensas Universitarias de Zaragoza.

Haye, A., Carvacho, H., González, R., Manzi, J., \& Segovia, C. (2009). Relación entre orientación política y condición socioeconómica en la cultura política chilena: una aproximación desde la psicología política. Polis, Revista de la Universidad Bolivariana, 8(23), 351-384.

Haye, A., Carvacho, H., \& Larraín, A. (2011). The ideological and the dialogical. Journal für Psychologie, 19(1).

Ibañez, J. (1992). Más allá de la sociología. El grupo de discusión: técnica y crítica. Madrid: Siglo XXI.

Íñiguez, L. (2003). El análisis del discurso en las ciencias sociales: variedades, tradiciones y práctica. En L. Íñiguez (Ed.). Análisis del discurso. Manual para las ciencias sociales, (pp. 83-123). Barcelona: Editorial UOC.

Jelin, E. (2002). Los trabajos de la memoria. Madrid: Siglo XXI.

Jelin, E., \& Langland, V. (Eds.) (2003). Monumentos, memoriales y marcas territoriales. Buenos Aires: Siglo XXI.

Lenz, C. (2011). Genealogy and Archeology: Analyzing Generational Positioning in Historical Narratives. Journal of Comparative Familiy Studies, 42(3), 319-327.

Mannheim, K. (1928). El problema de las generaciones. Revista Española de Investigaciones Sociológicas, 62, 193-242.

Manzi, J., Helsper, E., Ruiz, S., Krause, M., \& Kronmüller, E. (2004). El pasado que nos pesa: la memoria colectiva del 11 de septiembre de 1973. Revista de Ciencia Política, 22(2), 177-214.

Middleton, D., \& Edwards, D. (1992). Memoria compartida. La naturaleza del recuerdo y del olvido. Barcelona: Paidós.

Ministerio de Planificación, Gobierno de Chile (2006). Encuesta Casen. Santiago de Chile: Gobierno de Chile. 


\section{María José Reyes Andreani, Marcela Cornejo Cancino, María Angélica Cruz Contreras, Constanza Carrillo, Patricio Caviedes}

Misztal, B. (2003). Theories of social remembering. Maidenhead: Open University Press.

Muhr, T. (2009). ATLAS.ti The Knowledge Workbench: Visual Qualitative Data Analysis $\mathcal{E}$ Knowledge Management in Education, Business, Administration $\mathcal{F}$ Research (Version 6.0). Berlin: Scientific Software Development.

Piper, I. \& Hevia, E. (2012). Espacio y recuerdo: archipiélago de memorias en Santiago de Chile. Santiago: Ocho libros.

Potter, J. (1998). La representación de la realidad. Discurso, retórica y construcción social. Barcelona: Paidós.

Ramos, R. (1989). Maurice Halbwachs y la memoria colectiva. Revista de Occidente, 100, 63-81.

Raposo, G. (2012). Territorios de la memoria: La retórica de la calle en Villa Francia. Polis, 9(31), 1-15.

Reyes, Cornejo, Cruz, \& Banda, M. I. (2013a.) Imágenes para contar: memorias generacionales de la dictadura chilena a partir de la fotografías. Manuscrito sometido para publicación.

Reyes, Muñoz, J., \& Vásquez, F. (2013b.) Políticas de memoria desde los discursos cotidianos: la despolitización del pasado reciente en el Chile actual. Psykhe, 22(2), 161-173. http://dx.doi.org/10.7764/ psykhe.22.2.582

Reyes, M. (2009a). Política de memoria como producción cotidiana: la despolitización y la privatización del pasado reciente en el Chile actual. Tesis doctoral no publicada. Universidad Autónoma de Barcelona.

Reyes, M. (2009b). Generaciones de memoria: una dialógica conflictiva. Revista Praxis, 15, 77-97.

Reyes, L. (2004). Actores, conflicto y memoria: reforma curricular de historia y ciencias sociales en Chile, 1990-2003. En E. Jelin, \& F, Lorenz (Eds.). Educación y Memoria. La Escuela Elabora el Pasado. Buenos Aires: Siglo XX.
Rivero, I. (2003). Intertextualidad, polifonía y localización en investigación cualitativa. Athenea Digital, 3, 1-13.

Sandoval, J. (2013). Una perspectiva situada de la investigación cualitativa en ciencias sociales. Cinta de Moebio, 46, 37-46.

Schuman, H., \& Scott, J. (1989). Generations and collective memories. American Sociological Review, 54, 359-381.

Tocornal, X. (2008). The Chilean memory debate: Mapping the language of polarization. Disertación doctoral, Universidad de Loughborough.

Toledo, M.I., \& Magendzo, A. (2013). Golpe de Estado y dictadura militar: Estudio de un caso único de la enseñanza de un tema controversial en un sexto año básico de un colegio privado de la Región Metropolitana - Santiago, Chile. Psykhe, 22(2), 147-160. http://dx.doi.org/10.7764/psykhe.22.2.585

Traverso, E. (2007). El pasado, instrucciones de uso: historia, memoria, política (A. González de Cuenca, Trad.). Madrid: Marcial Pons.

Vasilachis de Gialdino, I. (2009). Los fundamentos ontológicos y epistemológicos de la investigación cualitativa. Forum: Qualitative Social Research,10(2), 30.

Vázquez, F. (2001). La memoria como acción social. Relaciones, significados e imaginario. Barcelona: Paidós.

Vázquez, F. (2002). Construyendo el pasado: la memoria como práctica social. Estudios Centroamericanos, 649-650, 1049-1065.

Veneros, D., \& Toledo, M.I. (2009). Del uso pedagógico de los lugares de memoria: visita de estudiantes de educación media al parque por la paz Villa Grimaldi (Santiago, Chile). Estudios Pedagógicos, 35(3), 199-220. 